\title{
ASO Visual Abstract: Do Preoperative Prophylactic Antibiotics Reduce Surgical-Site Infection After Wire-Localized Lumpectomy? A Single-Blind Randomized Clinical Trial
}

Gabrielle Bergeron Giguère, MD, Brigitte Poirier, MD, Louise Provencher, MD, Dominique Boudreau, MD, MA, Dominique Leblanc, MD, MSc, Éric Poirier, MD, Jean-Charles Hogue, PhD, Claudya Morin, PhD, and Christine Desbiens, MD

Centre des Maladies du Sein du CHU de Québec-Hôpital du Saint-Sacrement, Québec, Canada

This randomized clinical trial sought to determine whether the use of preoperative antibiotics reduces the rate of surgical-site infection after wire-localized lumpectomy (https://doi.org/10.1245/s10434-021-11031-9). The results showed no significant reduction. Obesity was the only significant risk factor identified.

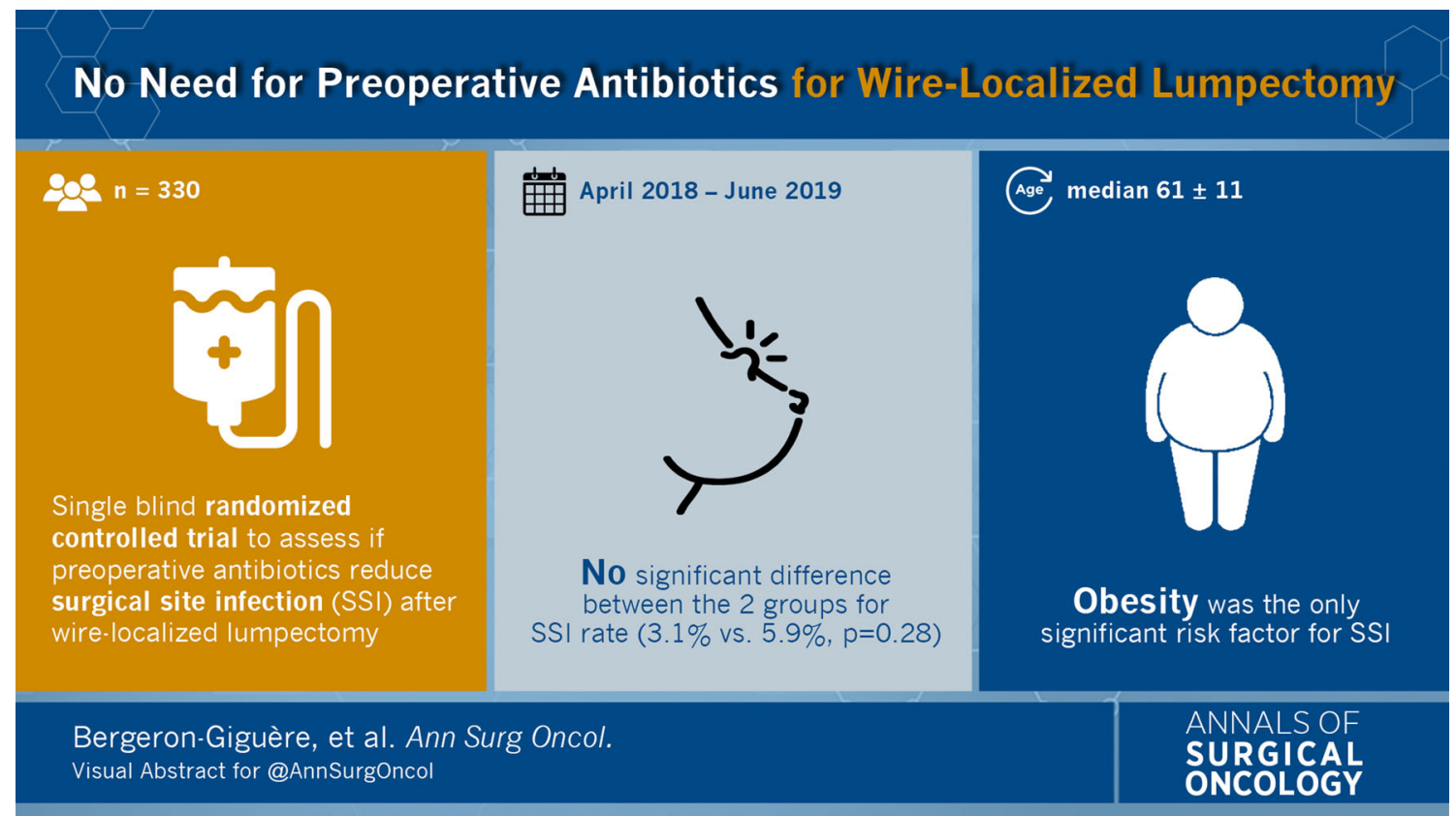

DISCLOSURE The authors declare that they have no conflicts of interest.

Publisher's Note Springer Nature remains neutral with regard to jurisdictional claims in published maps and institutional affiliations.

\footnotetext{
(C) Society of Surgical Oncology 2022

C. Desbiens, MD

e-mail: Christine.desbiens.med@ssss.gouv.qc.ca
} 